\title{
Critique
}

\section{Comments on "Antibacterial Effect of Five Zingiberaceae Essential Oils” by Laohakunjit et al., Molecules 2007, 12, 2047- 2060}

Received: 1 September 2007 / Accepted: 5 September 2007 / Published: 17 September 2007

Dear Editor:

The paper mentioned in the title of this letter, published in a recent issue of Molecules [1], contains, in my considered opinion, serious factual errors in the reported GC/MS identification of some components of the studied essential oils.

The correct identification of the components of natural extracts in publications is of extreme importance to the flavor and essential oil industries, as any errors can have far reaching implications in light of international legislation regulating the food flavor industry. Erroneous reports of this kind are actually fairly frequent, and emanate particularly from laboratories and research groups perhaps unfamiliar with the legal status of flavor and aroma constituents. For this reason guidelines for authors of papers concerning flavors and essential oils and the peer reviewers and publishers of such articles have recently been proposed by the International Organization of the Flavour Industry, in an attempt to ensure the correct identification of these components [2].

In the aforementioned article fraesol (1, ethyl 3-methyl-3-phenylglycidate, "strawberry aldehyde”, CAS 77-83-8 [3]) was identified as the major component of the essential oil of galanga (Alpinia galanga Sw.). This is a synthetic compound, never before identified in a natural source, which due to its structure is unlikely to be ever be found in Nature. The only possible explanation for its presence would be contamination of the studied plant sample, an extremely unlikely event. If truly present and under the chromatographic conditions described by the authors of this paper, this product should give two peaks with similar mass spectra, corresponding to the two possible cis and trans isomers of fraesol.

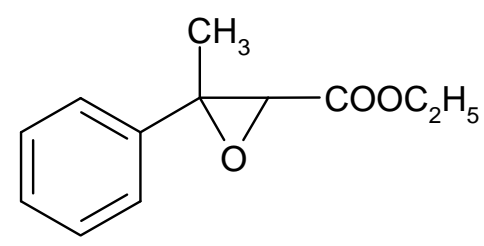

It is my opinion that the compound erroneously identified as fraesol (1) is either acetoxychavicol acetate, one of the major components of the essential oil of galanga rhizome [4] or ethyl trans-p- 
methoxycinnamate, which has a similar structure and identical molecular weight as fraesol and has been previously identified in the essential oil of Kaempheria galangal L. [5]. This is not the only error noted in this paper, as the compounds camphene, $\beta$-pinene, myrcene, $\beta$-phellandrene, linalyl acetate and bornyl acetate are all identified in incorrect positions.

In our R\&D laboratory, which specializes in the analysis of flavors and essential oils, positive identification of a compound is only claimed when there is a match for both the mass spectrum and the retention indices on two columns of different polarity and after comparison with an authentic reference sample, either isolated from a natural source or synthesized.

Sincerely,

Jose M. Bueno [6]

R\&D Manager,

Hausmann S.A.

San Andrés de la Barca, 08740

Barcelona (Spain)

E-mail: josem.bueno@hausmann.es

\section{References and Notes}

1. Norajit, K.; Laohakunjit N.; Kerdchoechuen, O. Antibacterial Effect of Five Zingiberaceae Essential Oils. Molecules 2007, 12, 2047-2060

2. International Organization of the Flavour Industry Working Group on Methods of Analysis. Statement on the identification in nature of flavouring substances, made by the Working Group on Methods of Analysis of the International Organization of the Flavour Industry (IOFI), Flavour Fragr. J. 2006, 21, 185.

3. Bauer, K.; Garbe, D.; Surburg, H. Common Fragrance and Flavor Materials: Preparation and Uses, Fourth Edition; Wiley-VCH Verlag GmbH: Weinheim, Germany, 2001

4. Janssen, A.M.; Scheffer, J.J.C. Acetoxychavicol acetate, an antifungal componenet of Alpinia galanga. Planta Medica 1985, 6, 507-511.

5. Wong, K.C.; Ong, K.S.; Lim, C.L., Composition of the essential oil of rhizomes of Kaempferia galanga L. Flavour Fragr. J. 1992, 7, 263-266.

6. Founding Member of the Spanish Society for Chromatography and Related Techniques (SECYTA) and the Spanish Society for Mass Spectrometry (SEEM).

(C) 2007 by MDPI (http://www.mdpi.org). Reproduction is permitted for noncommercial purposes. 